\title{
Intracardiac thrombi: diagnostic accuracy needs to be improved!
}

\author{
L. H. B. Baur
}

Received: 25 January 2007 / Accepted: 26 January 2007/Published online: 28 March 2007

(C) Springer Science+Business Media B.V. 2007

Intracardiac thrombi can occur in several disease states such as atrial fibrillation and myocardial infarction. In patients with a myocardial infarction left ventricular thrombi could be found in up to $30 \%$ of patients in the pre-thrombolytic and preacute angioplasty period but are now descibed in about $5 \%$ of patients in the GISSI study $[1,2]$. Most of these thrombi are related to an anteroseptal myocardial infarction and are located in the apex. Besides the locatization, other risk factors for mural thrombi are a reduced left ventricular ejection fraction and left ventricular aneurysm [2].

Left ventricular thrombi are associated with a high risk of systemic embolization. In some studies embolization was reported in $21 \%$ of patients [3]. Especially protruding and mobile thrombi have a high potential to embolize. Embolization may be prevented by proper anticoagulant therapy but carries the risk of fatal bleeding [4].

Two-dimensional echocardiography and transesophageal echocardiography are the most frequently used techniques to detect left ventricular thrombi. Unfortunately left ventricular thrombi are frequently missed by transthoracic and transesophageal echocardiography, especially in those

L. H. B. Baur ( $\square)$

Department of Cardiology, Atrium Medical Centre Parkstad, Henri Dunantstreet 5, 6401 CX Heerlen, The Netherlands

e-mail: lhbaur@yahoo.com patients in whom the acoustic window is not optimal. Therefore some experts recommend the use of an intravenous contrast agent to enhance detection of thrombi. In the currect issue of the International Journal of Cardiac Imaging Lipke et al. stress the value of contrast-enhanced cardiovascular magnetic resonance to detect left ventricular thrombi [5]. In $47 \%$ of the patients, where a left ventricular thrombus was seen with MR, this thrombus was missed by echocardiography. These findings are in agreement with the results of other investigators [6]. Especially small thrombi are frequently missed by echocardiography but can be detected with MRI. Because the potential benefit of oral anticoagulation in patients with a left ventricular thrombus and the potential harm in those patients without a thrombus contrast-enhanced MRI has to be used more liberal in patients after myocardial infarction. In those patients with a poor acoustic window MRI should become the first line technique for assessment of left ventricular thrombi. Although the higher costs, the paper of Lipke et al. stresses the importance of this strategy.

\section{References}

1. Van Dantzig JM, Delemarre BJ, Bot H, Visser CA (1996) Left ventricular thrombus in acute myocardial infraction. Eur Heart J 17:1640-1645

2. Chiarella F, Santoro E, Domenicucci S, Maggioni A; Vecchio C (1998) Predischarge two-dimensional echo- 
cardiographic evaluation of left ventricular thrombosis after acute myocardial infarction in the GISSI-3 study. Am J Cardiol 81:822-877

3. Visser CA; Kan G; Meltzer RS; Dunning AJ, Roelandt J (1985) Embolic potential of left ventricular thrombus after myocardial infarction: A two-dimensional echocardiographic study of 119 patients. J Am Coll Cardiol 6:1276-1280

4. Vaitkus PT, Barnathan ES (1993) Embolic potential, prevention and management of mural thrombus complicating anterior myocardial infraction: A meta-analysis. J Am Coll Cardiol 22:1004-1009

5. Lipke C, Katoh M, Franke A, Krombach G, Buecker A, Kühl H (2007) The value of non-contrast hermonic transthoracic echocardiography for the detection of left ventricular thrombi in patients with cardiomyopathy: comparison with contrast-enhanced magnetic resonance imaging. Int $\mathbf{J}$ Cardiac Imaging (in press)

6. Srichai MB, Junor C, Rodriguez L, Stillman AE, Grimm RA, Lieber ML, Waever JA, Smedira NG, White RD (2006) Clinical, imaging, and pathological characteristics of left ventricular thrombus: A comparison of contrast-enhanced magnetic resonance imaging, transthoracic echocardiography, and transesophageal echocardiography with surgical or pathological validation. Am Heart J 152:75-84 